\title{
EUROPA: CIVILIZACIÓN MORIBUNDA. CLAVES NIETZSCHEANAS
}

\author{
Carlos Javier Blanco Martín \\ Universidad de Oviedo
}

http://dx.doi.org/10.5209/rev_NOMA.2012.v35.n3.42193

Resumen.- De la mano de Nietzsche y Spengler, esbozaremos un diagnóstico sobre la Muerte de la Civilización Europea. La Civilización es la fase declinante de una Cultura, y haremos ver que los valores ilustrados e ideales de la Modernidad (Igualdad, Derecho, Estado nacional, Progreso) llevados hasta el fin en sus consecuencias son valores letales para la propia Civilización europea que los generó.

Palabras clave.- decadencia de Europa, Occidente, Igualdad, Derecho, Estado nacional, progreso

\section{Europe: dying civilization. Nietzschean keys}

Abstract.- Through Nietzsche's and Spengler's philosophy, we outline a diagnosis on the death of European civilization. Civilization is the declining phase of a culture, and we see that Enlightenment values and ideals of Modernity (Equality, Law, National State, Progress) led to the end in its consequences are lethal values for the true European civilization that generated them.

Keywords: decadence of Europe, the West, Equality, Law, national state, progress

\section{La mitología de la Igualdad}

El mundo que habíamos conocido hasta ahora se viene abajo. La oposición entre liberalismo occidental y comunismo del este ya es historia. En medio de dos mitologías totalitarias, la del Mundo-mercancía, de un lado, y la del igualitarismo, por el otro, los pueblos de Europa han descendido por la pendiente de la animalidad y la cosificación. Ya nada es como antes, y los viejos esquemas y categorías que permitían buscar aliados y detectar enemigos, son sistemas que fallan con estrépito.

Porque la Política, en gran medida y en el fondo, es eso: sistemas de detección de amigos y de enemigos, y métodos para forjar alianzas y destruir obstáculos. Europa dejó de ser en la gran guerra de 1939-1945. Nuestro continente, el mosaico de pueblos que un día fue reconocible como unidad, pasó a ser "Occidente". Al Este: el Comunismo...una sombra de Europa que supuestamente albergaría al "Proletariado Universal". Y frente a un Proletariado armado (que, según Marx, no tiene Patria) liderado por la URSS, se quiso alzar un no menos Universal Imperio de la Mercancía, el Capital y los Derechos Humanos: USA, Occidente.

Los dos grandes bloques imperialistas compartieron los mitos de la Igualdad y la Universalidad. Un escritor de segunda fila, Rousseau, fue canonizado como 
"filósofo de la Democracia". Mas esa Democracia como entidad absoluta no existe. Como sucede con todos los conceptos político-filosóficos, solo existen grados de democracia. En todo pueblo hay clases, estamentos, órdenes. El grado en que éstos han ejercido su poder sobre otros ha sido muy diverso en la historia europea. En todo caso siempre ha habido jerarquías, y la prevalencia de una visión burguesa del mundo y de su economía ha polarizado las luchas de clases- la voluntad de poder, si se quiere- entre poseedores de capital y productores directos. Pretender que en un mundo como éste, donde el dominio del Capital tiende a ser omnímodo, hay democracia también para el Pueblo desposeído de Capital (proletarios, productores directos del campo o de la fábrica) es pura fantasía ñoña de juristas. La democracia de Occidente es el nombre que se le da al sistema de dominio que garantiza a una clase el control y la manipulación de las restantes clases sociales con el fin de asegurarse los medios de obtención de la plusvalía. Ese sistema de dominio incluye propagar la ilusión en las clases sojuzgadas: la ilusión de que ellas también participan en el sistema y que pueden cambiarlo. La ilusión demográfica y aritmética que reza así: "somos más y reuniendo votos, podemos cambiar las leyes y corregir el sistema".

La igualdad como mitología procede de Rousseau, pero no en última instancia. Hunde raíces profundas en la religión cristiana, la fe de chandalas judíos, a decir de Nietzsche, la fe de impotentes que, reconociendo su propia impotencia, su enfermedad y mutilación, deseando la muerte por mor de su fracaso vital, no obstante albergó de manera retorcida su voluntad de poder. Una voluntad de poder, un deseo de vivir e imponerse a partir precisamente del instinto gregario estimulado por sus sacerdotes. El sacerdote paulino, un enfermo que puede conducir enfermos (pues a los sanos y vigorosos les perjudica el contacto con los portadores del miasma) es ese asceta que, sabiéndose mortificar infunde temor y respeto entre sus iguales en la enfermedad. Su astucia, su fingida humildad y dulzura, su aureola de conocedor de secretos arcanos y poderes invisibles, todo ayuda para camuflar su plebeya condición, su servil estatus de débil e impotente. Pero desde su debilidad e impotencia, desde su cosmopolitismo sin raíces ("universal") edifica Iglesias y predica a favor de una Hermandad de bestias bípedas que, nunca del todo domesticadas, anhelan Poder, anhelan someter y dominar. Ellos, los dominados y humillados, se arrodillan ante el Pastor, le siguen fanáticamente, porque él, enfermo entre enfermos, congrega rebaños que -andando el tiempodevienen masas.

Roma cayó por las masas, no por causa de los bárbaros. Las masas que una Iglesia paulina supo congregar y cuyos instintos de bestia resentida era preciso hacer converger contra aquello que de grande y noble había en Roma. La Cristiandad, el Medievo, fue luego el intento de Europa -esa red tupida de pueblos hermanos- por nacer. En los bosques de Germania, en los montes de las Asturias, subidos a las peñas de Castillos de roca y en aldeas remotas donde el arado y la espada se dieron la mano, la Cristiandad se pudo hacer guerrera por necesidad, abandonando la impotencia urbana y cosmopolita de los chandalas semitas. Pues, como bien sabía Spengler, la Historia del Cristianismo no es la Historia de una religión. Tenemos dos cristianismos: el mágico, es decir, el nacido en tiempos del Imperio decadente, como mezcla de 
creencias y ritos judaicos y cultura helenística popular. Ese cristianismo expresa el sentimiento de la cueva: todos los mortales se apiñan fraternal y universalmente bajo la bóveda celeste (reproducida en la cúpula oriental, que los propios romanos y bizantinos adaptaron antes del surgimiento de Mahoma y la mezquita). Pero a ese cristianismo mágico, orientalizante, le sucede -solo cronológicamente- un cristianismo faústico. El que nació en Covadonga, ya tempranamente, deteniendo al Islam en su avance hacia Europa. El que detuvo Carlos Martel y renació con los carolingios. De sus formas balbucientes, rurales y boscosas, en pleno siglo VIII hasta el esplendor del gótico, las cruzadas y la reconquista hay una línea de continuidad: el nacimiento de Europa como verdadera nación de naciones. Spengler captó perfectamente la discontinuidad, la incompatibilidad entre las almas de uno y otro cristianismo. Utilizar el mismo término para reflejar dos almas tan dispares no hace sino confundir.

\section{Teoría naturalista del Derecho}

El cristianismo mágico desvirtuó el Derecho, e hizo rara mixtura con el sistema jurídico de los romanos. Los pueblos germanos de Europa, desde el Duero hasta las llanuras centrales del continente, se regían por viejísimas constituciones consuetudinarias que eran honestas en cuanto a las relaciones de fuerza y a la jerarquía que establece privilegios y fidelidad. Estas normas eran vilipendiadas por eclesiásticos de la pseudomorfosis (esto es, los nostálgicos de las estructuras vacías y fosilizadas de las cristiandad romana tardía). El derecho de la pseudomorfosis -el del cristianismo "mágico"- no sabía hacer otra cosa que imponer la mentira: la universalidad de las almas, su horizontal sumisión a un Poder trascendente (vertical: el soberano, Dios) y la ocultación de los diversos poderes inmanentes, humanos.

El siguiente texto de Aurora, de F. Nietzsche, expresa meridianamente que el Derecho es Poder. El reconocimiento del otro y nuestros deberes hacia ellos son asuntos que no derivan de reglas abstractas, ya vengan de un Dios, un Soberano, un Libro. Son producto de un equilibrio entre el otro y mi yo. El equilibrio de que se trata es de fuerzas, de poder. Es mágico, sustancialista, creer que un sujeto es depositario de derechos. De lo que se trata es de cuántos derechos consiento que los otros tengan sobre mí.

112. Para la historia natural del deber y del derecho. Nuestros deberes no son otra cosa que los derechos que los demás tienen sobre nosotros. ¿Cómo adquirieron esos derechos?

Porque nos consideraron capaces de contraer compromisos y de cumplirlos, porque nos tuvieron por individuos iguales y semejantes a ellos, $y$, a causa de esto, nos prestaron algo, nos educaron y mantuvieron. Al cumplir, pues, nuestro deber, respondemos a la idea que otros han tenido respecto a nuestra capacidad y a la que debemos el bien que nos han hecho, y devolvemos en la misma medida lo que hemos recibido. Es, pues, nuestro orgullo quien nos exige cumplir nuestros deberes; tratamos de ser autónomos, correspondiendo a lo que otros hicieron por nosotros con algo que nosotros hacemos por ellos. Los otros, al beneficiarnos, invadieron el área de nuestro poder, y habrían 
dejado allí permanentemente su huella, si nosotros no hubiéramos llevado a cabo una represalia: cumpliendo con nuestro deber, invadimos por nuestra parte el área de poder de aquéllos. Los derechos que los demás tienen sobre nosotros sólo pueden afectar a aquello que entra dentro de nuestro poder, a lo que podemos hacer, pues sería absurdo que nos exigieran imposibles. Habrá que decir, más exactamente, que los derechos afectan sólo a lo que los otros consideran que está dentro de nuestro poder, siempre y cuando sea lo mismo que nosotros pensamos que podemos hacer. Por una parte o por otra se puede incurrir fácilmente en el error. El sentido del deber exige que creamos lo mismo que los demás cuál es el alcance de nuestro poder; o, lo que es igual, que podamos prometerdeterminadas cosas y comprometernos a llevarlas a cabo. ${ }^{1}$

\footnotetext{
${ }^{1}$ Traducción de Francisco Javier Carretero. Edición de Distribuciones Mateo. Madrid, 1994. La versión alemana del aforismo 112 es la siguiente:
}

"Zur Naturgeschichte von Pflicht und Recht. - Unsere Pflichten - das sind die Rechte Anderer auf uns. Wodurch haben sie diese erworben? Dadurch, dass sie uns für vertrags- und vergeltungsfähig nahmen, für gleich und ähnlich mit sich ansetzten, dass sie uns daraufhin Etwas anvertrauten, uns erzogen, zurechtwiesen, unterstützten. Wir erfüllen unsre Pflicht - das heißt: wir rechtfertigen jene Vorstellung von unserer Macht, auf welche hin uns Alles erwiesen wurde, wir geben zurück, in dem Maße, als man uns gab. So ist es unser Stolz, der die Pflicht zu tun gebeut, - wir wollen unsre Selbstherrlichkeit wiederherstellen, wenn wir dem, was Andre für uns taten, Etwas entgegenstellen, das wir für sie tun, - denn Jene haben damit in die Sphäre unserer Macht eingegriffen und würden dauernd ihre Hand in ihr haben, wenn wir nicht mit der "Pflicht" eine Wiedervergeltung übten, das heißt in ihre Macht eingriffen. Nur auf Das, was in unsrer Macht steht, können sich die Rechte Anderer beziehen; es wäre unvernünftig, wenn sie Etwas von uns wollten, das uns selber nicht gehört. Genauer muss man sagen: nur auf Das, was sie meinen, dass es in unserer Macht steht, voraussetzend, dass es das Selbe ist, von dem wir meinen, es stehe in unserer Macht. Es könnte leicht auf beiden Seiten der gleiche Irrtum sein: das Gefühl der Pflicht hängt daran, dass wir in Bezug auf den Umkreis unserer Macht den selben Glauben haben, wie die Anderen: nämlich dass wir bestimmte Dinge versprechen, uns zu ihnen verpflichten können ("Freiheit des Willens"). Meine Rechte: das ist jener Teil meiner Macht, den mir die Anderen nicht nur zugestanden haben, sondern in welchem sie mich erhalten wollen. Wie kommen diese Anderen dazu? Einmal: durch ihre Klugheit und Furcht und Vorsicht: sei es, dass sie etwas Ähnliches von uns zurückerwarten (Schutz ihrer Rechte), dass sie einen Kampf mit uns für gefährlich oder unzweckmäßig halten, dass sie in jeder Verringerung unserer Kraft einen Nachteil für sich erblicken, weil wir dann zum Bündnis mit ihnen im Gegensatz zu einer feindseligen dritten Macht ungeeignet werden. Sodann: durch Schenkung und Abtretung. In diesem Falle haben die Anderen Macht genug und übergenug, um davon abgeben zu können und das abgegebene Stück Dem, welchem sie es schenkten, zu verbürgen: wobei ein geringes Machtgefühl bei Dem, der sich beschenken lässt, vorausgesetzt wird. So entstehen Rechte: anerkannte und gewährleistete Machtgrade. Verschieben sich die Machtverhältnisse wesentlich, so vergehen Rechte und es bilden sich neue, - dies zeigt das Völkerrecht in seinem fortwährenden Vergehen und Entstehen. Nimmt unsere Macht wesentlich ab, so verändert sich das Gefühl Derer, welche bisher unser Recht gewährleisteten: sie ermessen, ob sie uns wieder in den alten Vollbesitz bringen können, - fühlen sie sich hierzu außer Stande, so leugnen sie von da an unsere "Rechte". Ebenso, wenn unsere Macht erheblich zunimmt, verändert sich das Gefühl Derer, welche sie bisher anerkannten und deren Anerkennung wir nun nicht mehr brauchen: sie versuchen wohl, dieselbe auf das frühere Maß herabzudrücken, sie werden eingreifen wollen und sich auf ihre "Pflicht" dabei berufen, - aber dies ist nur ein unnützes Wortemachen. Wo Recht herrscht, da wird ein Zustand und Grad von Macht aufrecht erhalten, eine Verminderung und Vermehrung abgewehrt. Das Recht Anderer ist die Konzession unseres Gefühls von Macht an das Gefühl von Macht bei diesen Anderen. Wenn sich unsere Macht tief erschüttert und gebrochen zeigt, so hören unsere Rechte auf: dagegen hören, wenn wir sehr viel mächtiger geworden sind, die Rechte Anderer für uns auf, wie wir sie bis jetzt ihnen zugestanden. - Der "billige Mensch" bedarf fortwährend des feinen Taktes einer Wage: für die Macht- und Rechtsgrade, welche, bei der vergänglichen Art der menschlichen Dinge, immer nur 
En las relaciones inmanentes con los otros, la esfera del yo puede ser invadida no ya solo por medio de asaltos, robos, insultos. La propia solicitud del otro, la predisposición suya a hacerme el bien me condiciona o me determina: crea en mí obligaciones y al hacerlo, se resta mi poder.

Nuestros derechos son la parte de nuestro poder que los demás no sólo nos reconocen sino que quieren que conservemos. ¿Por qué razón? Unas veces, por prudencia, por miedo o por discreción, bien porque esperan de nosotros algo similar (la protección de sus derechos), bien porque consideran que sería peligroso e inoportuno enfrentarse con nosotros, o bien porque juzguen que si nuestra fuerza disminuye, ellos saldrán perjudicados, dado que entonces no podremos ayudarles frente a un tercero. Otras veces, el motivo puede ser la donación y la cesión, o bien hay que admitir un cierto sentimiento de poder en quien recibe la concesión.

He aquí, pues, cómo se originan los derechos: son grados de poder reconocidos y garantizados. Si las relaciones existentes entre distintos poderes se modifican de una forma sustancial, desaparecen unos derechos y surgen otros, como lo demuestra el constante vaivén del derecho de los pueblos. Si disminuye mucho nuestro poder, variará también el sentir de quienes hasta ese momento garantizaban nuestros derechos: examinarán las razones que tenían para otorgarnos nuestra posesión, y si el examen nos es desfavorable, nos negarán nuestros derechos.

Todo esto significa formular una teoría anti-metafísica del Derecho: una teoría mucho más cercana a los hechos básicos de la existencia humana en tanto que esa existencia es lucha y coexistencia de animales que se miden las fuerzas unos a otros sin cesar, vigilando quién dará el primer golpe, tratando de corresponder a los golpes del otro, coaligándose y traicionándose, haciendo pactos para derramar sangre ajena, o derramando sangre ajena para conseguir pactos. Sin embargo no es el bellum omnium contra omnes, de un Hobbes o de un darwinista social lo que Nietzsche nos enseña aquí. La propia paz, la existencia de treguas y cooperaciones, se entiende en términos de relatividad entre sujetos y de condiciones materiales inmanentes. No es una guerra loca por la supervivencia. La "fuerza" que se presume en la teoría naturalista del derecho no es una sustancia física que se deposita unívocamente en cada sujeto para atribuirse así, de forma inmediata, los "derechos". Esta no es una fuerza física, sino que es fuerza etológica: implica causalidades a distancia. Esto quiere decir que lo que resulta decisivo es aparentar la fuerza más que poseerla. Importa mucho más ser evaluado como fuerte, o percibir la fuerza supuesta de otros. No hay sustancia, sólo relaciones recíprocas. El derecho posee una historia natural que solo se entiende a la luz de la etología. La propia historia de la humanidad no tiene nada que ver con un aumento continuo

eine kurze Zeit im Gleichgewichte schweben werden, zumeist aber sinken oder steigen: - billig sein ist folglich schwer und erfordert viel Übung, viel guten Willen und sehr viel sehr guten Geist. — [disponible en http://www.textlog.de/nietzsche-morgen.html] 
de libertades, de derechos, de "conquistas sociales". Lo que se ofrece, como propaganda, como mentira, en términos de logro conquistado no siempre fue realmente conquistado. En ocasiones fue otorgado, simplemente. $Y$ en todo caso lo recibido y ganado puede perderse. La vieja Europa, por ejemplo, esa civilización cansada que hasta hace poco se creyó cuna y reducto de las "conquistas sociales", bien puede experimentar todo signo de "retrocesos" si por tales entendemos la impugnación y reapropiación de lo que un día fue concedido. Y esto será así no tanto por parte de un (Estado) soberano, que reclame lo suyo, sino por los verdaderos beneficiarios de la acumulación de capital. Para los capitalistas aquel (Estado) soberano largamente erigido a sangre y fuego por encima de pueblos, soberanías históricas, comunidades campesinas, tradiciones inveteradas, ahora no es más que un instrumento de subordinación al mercado global. El Estado fue sagrado para la burguesía autotitulada de "nacional" mientras aquella sacralización fue útil en sus proyectos de acumulación. Ahora los Estados "nacionales", y especialmente aquellos que sirvieron de colonias económicas de los estados fuertes, se muestran como castillos de paja que un fuerte huracán financiero puede borrar. La contingencia de sus Constituciones, la debilidad y patraña de sus marcos jurídicos, se hará más y más evidente.

En el mismo párrafo 112 de Aurora, todo este esbozo nietzscheano de una Teoría Naturalista del Derecho, léase, del Poder, se ofrece finalmente una concepción de la equidad. Lejos de entenderse el Derecho como un deber ser que pugna por cumplirse en una realidad, ser, imperfecto y calumniado (todo idealismo y platonismo jurídicos descansan en esta idea), Nietzsche invierte los planos. Es una realidad dinámica, fluida, cambiante la que contiene una constante estimación de las fuerzas propias y ajenas. Esa estimación en medio de las luchas la que fuerza al reconocimiento de los privilegios ajenos o a la revisión de la confianza en los míos propios. No hay un deber ser: la norma, el equilibrio, la mesura mayor o menor para con los otros, todo esto debe iluminarse de acuerdo con una teoría etológica del Poder:

Si, por el contrario, nuestro poder aumenta en un grado considerable, cambiará también el sentir de quienes nos reconocían ese poder, en el sentido de que tratarán de reducir nuestro poder a sus límites primitivos y procurarán interferirse en nuestros asuntos apelando a sus deberes. Con todo, estas palabras resultan inútiles. Dondequiera que reine el derecho, que se mantenga un estado y que se ostente un grado determinado de poder, se rechazarán todo aumento o disminución de éste. El derecho que reconocemos a los demás es una concesión del sentimiento de nuestro poder al sentimiento del poder ajeno. Cuando nuestro poder se resquebraja profundamente y se rompe, cesan nuestros derechos; $y$, a la inversa, cuando nos hacemos más poderosos, los derechos ajenos dejan de ser para nosotros lo que eran hasta entonces.

El hombre equitativo necesita, pues, la sutil sensibilidad de una balanza para calibrar los grados de poder y de derecho que, dada la precariedad de las cosas humanas, se mantienen muy raras veces en equilibrio, siendo lo más común que bajen y suban con frecuencia. Por consiguiente, es difícil ser equitativo, y requiere mucha experiencia, mucha buena voluntad, $y$, sobre todo, mucho ingenio. 
La inflación del Derecho, en nuestra cansada Europa, se corresponde también con la vigencia -a todas luces injustificada- de la idea de Estado (y peor aún: de un Estado nacional) que justifique lo mejor y lo mayor de los esfuerzos humanos. El sustituto de Dios en la tierra, o la pretendida suplantación de la divinidad que la Modernidad nos deparó con su idea absoluta del Estado, son empresas que están llegando a su fin. En los nubarrones lejanos del porvenir (el sino, das Schicksal, diría Spengler) se adivinan imperios, grandes bloques continentales de Poder. El Estado nacional europeo se vislumbra cada vez más como una entidad ridículamente pequeña, como un juguete arrojado en medio del campo de batalla mundial, en donde se pelea con armas de verdad. Ya Alejandro y Roma debieron ver así a las poleis griegas. Como miniaturas arcaicas y, he aquí lo decisivo, como ficciones impotentes. El entramado de leyes, la actividad legislativa, el orgullo patrio y la aspiración a conservar alguna clase de la vieja soberanía, todo eso, se viene a bajo por obra de una verdadera fuerza disgregadora. Por abajo, los Estados "nacionales" se mostrarán, de nuevo, bajo su aspecto más plural, heterogéneo y premoderno: como mosaicos de pueblos, como comunidades étnicas diferenciadas que un día, para mayor gloria de la Corona, hubieron de nivelarse y subordinarse. Se trataba de crear mercados de ámbito mayor, bajo control centralizado, así como de buscar la máxima homogeneidad étnica para potenciar así la homogeneidad jurídica que exigía el Capitalismo.

El proceso que aquí se describe supuso una simplificación jurídica y, por ende, una nueva jerarquización social basada en criterios puramente económicos (en el siglo XIX se consuma ese proceso, aboliéndose en España, p.e. la distinción entre hidalgos y plebeyos que, bajo el capitalismo, ya había dejado de ser operativa mucho antes). La jerarquía del medievo tardío, que todavía se hacía oír con fuerza en el siglo XVIII, se desploma precisamente bajo la nivelación de un nuevo Derecho que, partiendo de la Monarquía Administrativa (siguiendo en cuanto a terminología a M. Foucault), pasando por el Absolutismo hasta llegar al nacionalismo liberal, ha convertido al Derecho en una máquina plegada al Capital: el orden complejo de jerarquías feudales se sustituye por la jerarquía clasista. El Derecho centrado en la mercancía, el absolutismo de la Mercancía inunda toda otra consideración, desploma toda jerarquía "natural". El control de los medios de producción (Marx) y la segregación de nuevas clases parasitarias que traten de imitar a las antiguas noblezas (por vía de la emulación, la ostentación, el derroche: vide Veblen).

\section{Muerte del Estado. Fin de la Gran Política}

La Economía política, bajo un disfraz frío, aséptico y pacífico, subordinó en términos de "competencia" toda lucha y voluntad de poder. Se dio a sí misma la faz de ciencia fría y objetiva pero en realidad fue la más eficaz prédica a favor del ascetismo. Los vínculos entre Economía política (como ciencia reina en el capitalismo) y ascetismo han sido señalados por los grandes clásicos: Marx, Nietzsche, Weber. La propia política, la "gran política" de los reyes soberanos, de las cortes europeas, de los imperios coloniales, ese arte al servicio de una gran Voluntad de Poder, pareció rebajarse al nivel de la simple triquiñuela de tenderos. La idea de un Estado como "camarilla de empleados al servicio del 
Capital", aunque refleja la más tosca versión marxista de su teoría política, no dejó de corresponderse con una evidencia real. La Gran Política moría bajo el influjo de negociantes y tenderos. El propio Estado empezó a verse como una prolongación de los asuntos mercantiles y una excrecencia necesaria para la acumulación de la plusvalía. Ello fue parejo a una retirada de escena de los sacerdotes como enfermos conductores de una grey (ahora, masa). La disciplina introducida por los sacerdotes, la domesticación de la "bestia rubia", su encarcelamiento en monasterios y en ideales ascéticos, la pacificación de las razas y la represión de sus estratos más nobles, todo eso, puede llevarlo a cabo con redoblada eficacia el ascetismo del trabajo. Regirse por horarios fijos, volver a casa agotado, no disponer de tiempo para pensar, envolverse en la nube de "moscas del mercado", que el ruido de las tiendas e industrias y el tráfago de la vida impidan que los "perros enjaulados" de la conciencia se hagan oír. El Estado comienza a ser "asunto público" (democratismo, sufragio universal) justamente en el momento histórico en que de veras se está convirtiendo en esa "camarilla de empleados al servicio del Capital". Las élites del mundo tradicional nunca hubieran dejado el Estado en manos del pueblo. Y desde el siglo XIX la ilusión roussoniana de la Voluntad General sirve, de manera prodigiosa, a los propósitos de potenciar el verdadero Poder: el de la clase (tomada como un todo) burguesa que controla los medios de producción y que anhela, única y exclusivamente, acumular plusvalía y apropiársela.

Muere la Gran Política, y el Estado liberal se presenta como el Estado de todos, como el Estado de la soberanía popular y de la voluntad general, donde las masas "opinan" pero al mismo tiempo perecen en su humanidad entre las tenazas de la alienación técnica y la explotación laboral. Por esto mismo, del hecho de que el propio Estado sea un instrumento para la explotación de las clases subalternas y una máscara de la explotación y de la jerarquía de privilegios, hace que él, como entidad digna de análisis, no constituya la razón última de quien quiera, como Nietzsche, emprender la transvaloración de todos los valores.

179. La menor cantidad de «Estado» posible. Todo el conjunto de condiciones políticas y sociales no valen lo suficiente para que las inteligencias más capacitadas se vean obligadas y tengan la necesidad de ocuparse de ellas. Semejante despilfarro de inteligencia es mucho más grave que un estado de miseria. La política es el campo de acción de cerebros mediocres, y este campo no debería estar abierto a los espíritus más elevados, aunque la máquina se haga pedazos. Pero, tal como están hoy las cosas, cuando todos no sólo se creen con derecho a estar informados diariamente de los asuntos políticos, sino que quieren intervenir activamente en ellos y abandonan por esto su trabajo, la locura no puede ser mayor ni más ridícula. A este precio, pagamos muy cara la seguridad pública; y lo más absurdo es que, por este medio, se consigue precisamente lo contrario, como lo está demostrando nuestro excelente siglo, de una forma desconocida hasta ahora. Proteger a la sociedad contra los ladrones e incendiarios, hacerla lo más cómoda posible para toda clase de comercio y de relaciones, y convertir al Estado en la Providencia (en el bueno o en el mal sentido), son fines inferiores, secundarios $y$ en absoluto indispensables, a cuyo servicio no deberían estar los fines e instrumentos más elevados de que se dispongan, los cuales habrán de 
reservarse para los fines superiores y más extraordinarios. Aunque nuestra época habla mucho de economía, es bastante pródiga. Despilfarra lo más preciado: la inteligencia. ${ }^{2}$

Una teoría instrumentalista del Estado, casi liberal, que impida cualquier género de divinización del mismo, es lo que ofrece Nietzsche en éste párrafo de Aurora. El Estado, "el más frío de los monstruos", no debería focalizar la atención de las mejores mentes. Pero la nube de humo de los periódicos, el establecimiento de una sociedad de masas y, por ende, de "opinión pública" es lo que ha hecho que el Estado adquiera un rango ontológico desmesurado. Pero en realidad, ese Estado que se pretende de todos, como fin último y como Dios con piernas que camina por la tierra, ese Estado no debería pasar de ser un instrumento defensivo de la comunidad. Ahora, con más motivos, el Estado va ofreciéndose a la mirada sagaz como una circunscripción administrativa por la que no vale la pena morir, matar, ni tampoco desvelarse. Por encima de su tamaño (Imperios, bloques continentales) y por debajo (pueblos, nacionalidades, regiones) hay otras lógicas de lo humano, si hacemos abstracción de la lógica imperiosa en el Capitalismo: la creación, acumulación y apropiación de capital.

Pero el establecimiento de jerarquías es un proceso natural, y choca con estrépito con las ilusiones de Rousseau, de los teóricos del Pacto Social o los predicadores de los Derechos Humanos y la Democracia Universal. La defensa de la dignidad del hombre no pasa por la compasión universal (con la que Schopenhauer quiso edificar la ética, en contra de Kant). Tampoco cabe la defensa de la dignidad del hombre desde una instancia puramente jurídica, atendiendo al positivismo más craso. Bastaría convertir la ONU en un gobierno mundial y dotar de plenos poderes a una serie de Tribunales Internacionales para "hacer que se cumplan" los Derechos Humanos. Tal punto de vista, la confianza ciega en un progreso institucional y en una legislación internacional, es de todo punto infantil. Ni una compasión universal, ni una legislación igualmente universal son los medios para "arreglar el mundo". En el fondo, tales puntos de vista se complementan y poseen una raíz netamente religiosa,

\footnotetext{
2 179. So wenig als möglich Staat! - Alle politischen und wirtschaftlichen Verhältnisse sind es nicht wert, dass gerade die begabtesten Geister sich mit ihnen befassen dürften und müssten: ein solcher Verbrauch des Geistes ist im Grunde schlimmer, als ein Notstand. Es sind und bleiben Gebiete der Arbeit für die geringeren Köpfe, und andere als die geringen Köpfe sollten dieser Werkstätte nicht zu Diensten stehen: möge lieber die Maschine wieder einmal in Stücke gehen! So wie es aber jetzt steht, wo nicht nur Alle täglich darum glauben wissen zu müssen, sondern auch Jedermann alle Augenblicke dafür tätig sein will und seine eigene Arbeit darüber im Stiche lässt, ist es ein großer und lächerlicher Wahnsinn. Man bezahlt die "allgemeine Sicherheit" viel zu teuer um diesen Preis: und, was das Tollste ist, man bringt überdies das Gegenteil der allgemeinen Sicherheit damit hervor, wie unser liebes Jahrhundert zu beweisen unternimmt: als ob es noch nie bewiesen wäre! Die Gesellschaft diebessicher und feuerfest und unendlich bequem für jeden Handel und Wandel zu machen und den Staat zur Vorsehung im guten und schlimmen Sinne umzuwandeln, - dies sind niedere, mäßige und nicht durchaus unentbehrliche Ziele, welche man nicht mit den höchsten Mitteln und Werkzeugen erstreben sollte, die es überhaupt gibt, — den Mitteln, die man eben für die höchsten und seltensten Zwecke sich aufzusparen hätte! Unser Zeitalter, so viel es von Ökonomie redet, ist ein Verschwender: es verschwendet das Kostbarste, den Geist." [íbíd.]
} 
sacerdotal. Nietzsche nos advierte que detrás del sacerdote, como heredero suyo, con otras sotanas y otras biblias, está el filósofo (Rousseau, Kant, Schopenhauer, Hegel...). Y detrás del filósofo, ese hombre que predica y que legisla, ora divinizando al Estado, ora haciendo divino el corazón del hombre, es en realidad una encarnación de la voluntad de poder. La voluntad del pequeño, del débil, del mellado y domesticado hombre ascético que se crece con su inteligencia, su cultura, su voracidad de opiniones, doctas 0 periodísticas...esa voluntad no deja de ser voluntad de poder, pero las acciones que dimanan de ella no brotan de forma natural o espontánea, de un don. Brotan del resentimiento, de la acumulación del deseo de venganza.

El Estado nacional, de ser "Dios en la tierra" se ha rebajado a lacayo del Capital. De ser fin absoluto, a mero instrumento. El Estado nacional ha creado para sí a las masas, al proletariado, la urbe, las "ideas modernas" (en expresión nietzscheana), la opinión pública. Pero tras estos tristes y plebeyos partos, se deshace en su gris vulgaridad. Ha cumplido su función, matando anteriores jerarquías, desvencijando el campo y toda índole de comunidades naturales. Ahora le toca morir y devolver a la Historia sus tendencias propias, su sino en sentido spengleriano: pueblos, etnias, nacionalidades, por debajo, y grandes espacios imperiales, por encima. En medio se mueve el individuo laminado, el átomo social del consumismo. En la época en que Nietzsche vivió, aún no se habían deducido todas las consecuencias de una sociedad de masas y de gran consumo opulento y del "Estado del bienestar". Los Estados "nacionales" y la propia fortificación de una Gran Alemania (Reich) pugnaban en su mente. La decadencia europea señalada por el filósofo era moral, y los signos políticoeconómicos de ella no presentaban la rotundidez con que hoy se nos muestran. En Nietzsche, además, se da una antítesis entre Norte (campesino, tosco) y Sur (urbano, sutil) muy curiosa e interesante. Cuando hace referencia a la Iglesia (Romana) ésta es presentada como ruina de una institución más perfecta, más sabia, pero ruina al fin, en comparanza con las creaciones toscas de los nórdicos (Estados, en suma, forjados por la violencia pura y dura frente a la dominación más retorcida del Catolicismo supranacional). Léase el siguiente aforismo de La Gaya Ciencia:

358. La sublevación de los campesinos en el terreno del espíritu. Los europeos nos encontramos frente a un inmenso conjunto de ruinas, en el que se alzan aún varias obras elevadas, en el que subsisten muchas cosas carcomidas y de aspecto inquietante, mientras que la mayor parte se ha hundido y cubre el suelo plagado de malezas, grandes y pequeñas, produciendo en su totalidad un efecto muy pintoresco. ¿Dónde hubo nunca ruinas más bellas?

Esta ciudad en ruinas es la Iglesia. Observamos la sociedad religiosa del cristianismo sacudida hasta sus últimos cimientos. La fe en Dios ha sido derribada, demolida, mientras que la nos ha redimido aún en modo alguno el pesimismo reciente. También las "ideas modernas" demuestran aún esa sublevación de campesinos en el norte contra el espíritu más frío, más equívoco, más desconfiado del sur, cuyo monumento más grandioso es la Iglesia cristiana. No olvidemos, en definitiva, lo que representa una Iglesia, principalmente por oposición a cualquier "Estado"; una Iglesia es ante todo una estructura de dominio que asegura al hombre más espiritual el rango supremo 
y que cree en el poder de la espiritualidad, a fin de prohibirse todo recurso a medios de violencia más toscos; sólo por eso, la Iglesia es, en todos los sentidos, una institución más noble que el Estado. ${ }^{3}$

${ }^{3}$ El aforismo 258, completo, de La Gaya Ciencia, en su original alemán es el siguiente: Der Bauernaufstand des Geistes. - Wir Europäer befinden uns im Anblick einer ungeheuren Trümmerwelt, wo Einiges noch hoch ragt, wo Vieles morsch und unheimlich dasteht, das Meiste aber schon am Boden liegt, malerisch genug - wo gab es je schönere Ruinen? - und überwachsen mit großein und kleinem Unkraute. Die Kirche ist diese Stadt des Untergangs: wir sehen die religiöse Gesellschaft des Christentums bis in die untersten Fundamente erschüttert, - der Glaube an Gott ist umgestürzt, der Glaube an das christlich-asketische Ideal kämpft eben noch seinen letzten Kampf. Ein solches lang und gründlich gebautes Werk wie das Christentum - es war der letzte Römerbau! - konnte freilich nicht mit Einem Male zerstört werden; alle Art Erdbeben hat da rütteln, alle Art Geist, die anbohrt, gräbt, nagt, feuchtet, hat da helfen müssen. Aber was das Wunderlichste ist: Die, welche sich am meisten darum bemüht haben, das Christentum zu halten, zu erhalten, sind gerade seine besten Zerstörer geworden, - die Deutschen. Es scheint, die Deutschen verstehen das Wesen einer Kirche nicht. Sind sie dazu nicht geistig genug? nicht misstrauisch genug? Der Bau der Kirche ruht jedenfalls auf einer südländischen Freiheit und Freisinnigkeit des Geistes und ebenso auf einem südländischen Verdachte gegen Natur, Mensch und Geist, — er ruht auf einer ganz andren Kenntnis des Menschen, Erfahrung vom Menschen, als der Norden gehabt hat. Die Lutherische Reformation war in ihrer ganzen Breite die Entrüstung der Einfalt gegen etwas "Vielfältiges", um vorsichtig zu reden, ein grobes biederes Missverständnis, an dem Viel zu verzeihen ist, - man begriff den Ausdruck einer siegreichen Kirche nicht und sah nur Korruption, man missverstand die vornehme Skepsis, jenen Luxus von Skepsis und Toleranz, welchen sich jede siegreiche selbstgewisse Macht gestattet ... Man übersieht heute gut genug, wie Luther in allen kardinalen Fragen der Macht verhängnisvoll kurz, oberflächlich, unvorsichtig angelegt war, vor Allem als Mann aus dem Volke, dem alle Erbschaft einer herrschenden Kaste, aller Instinkt für Macht abging: so dass sein Werk, sein Wille zur Wiederherstellung jenes Römer-Werks, ohne dass er es wollte und wusste, nur der Anfang eines Zerstörungswerks wurde. Er dröselte auf, er riss zusammen, mit ehrlichem Ingrimme, wo die alte Spinne am sorgsamsten und längsten gewoben hatte. Er lieferte die heiligen Bücher an Jedermann aus, - damit gerieten sie endlich in die Hände der Philologen, das heißt der Vernichter jeden Glaubens, der auf Büchern ruht. Er zerstörte den Begriff "Kirche", indem er den Glauben an die Inspiration der Konzilien wegwarf: denn nur unter der Voraussetzung, dass der inspirierende Geist, der die Kirche gegründet hat, in ihr noch lebe, noch baue, noch fortfahre, sein Haus zu bauen, behält der Begriff "Kirche" Kraft. Er gab dem Priester den Geschlechtsverkehr mit dem Weibe zurück: aber drei Viertel der Ehrfurcht, deren das Volk, vor Allem das Weib aus dem Volke fähig ist, ruht auf dem Glauben, dass ein Ausnahme-Mensch in diesem Punkte auch in andren Punkten eine Ausnahme sein wird, - hier gerade hat der Volksglaube an etwas Übermenschliches im Menschen, an das Wunder, an den erlösenden Gott im Menschen, seinen feinsten und verfänglichsten Anwalt. Luther musste dem Priester, nachdem er ihm das Weib gegeben hatte, die Ohrenbeichte nehmen, das war psychologisch richtig: aber damit war im Grunde der christliche Priester selbst abgeschafft, dessen tiefste Nützlichkeit immer die gewesen ist, ein heiliges Ohr, ein verschwiegener Brunnen, ein Grab für Geheimnisse zu sein. "Jedermann sein eigner Priester" - hinter solchen Formeln und ihrer bäurischen Verschlagenheit versteckte sich bei Luther der abgründliche Hass auf den "höheren Menschen" und die Herrschaft des "höheren Menschen", wie ihn die Kirche conzipiert hatte: - er zerschlug ein Ideal, das er nicht zu erreichen wusste, während er die Entartung dieses ldeals zu bekämpfen und zu verabscheuen schien. Tatsächlich stiess er, der unmögliche Mönch, die Herrschaft der homines religiosi von sich; er machte also gerade Das selber innerhalb der kirchlichen Gesellschafts-Ordnung, was er in Hinsicht auf die bürgerliche Ordnung so unduldsam bekämpfte, - einen "Bauernaufstand". - Was hinterdrein Alles aus seiner Reformation gewachsen ist, Gutes und Schlimmes, und heute ungefähr überrechnet werden kann, - wer wäre wohl naiv genug, Luthern um dieser Folgen willen einfach zu loben oder zu tadeln? Er ist an Allem unschuldig, er wusste nicht was er tat. Die Verflachung des europäischen Geistes, namentlich im Norden, seine Vergutmütigung, wenn man's lieber mit einem moralischen Worte bezeichnet hört, tat mit der Lutherischen Reformation einen tüchtigen Schritt vorwärts, es 
Esos "campesinos del Norte" quizá hagan referencia a Lutero, a la Reforma protestante que estuvo en la base de la formación de Iglesias nacionales y, por tanto, de la propia Alemania como nación frente a una Catolicidad Romana. Carlos V y los Austrias españoles fueron, posiblemente, los últimos "césares" del catolicismo. Su proyecto era, esencialmente, imperial y católico, es decir: anti-nacional. En ellos latía todavía el impulso de la latinidad. El deseo de la pseudomorfosis imperial romana por sobrevivirse, por emplear todos los medios y la sangre para levantar un cadáver y extender su sombra sobre la aldea, sobre el bosque, sobre una barbarie que empezaba a despertar en Europa de su modorra, tuvo en estos proyectos imperiales su aspecto activo, que Nietzsche oscurece. Prefiere quedarse solamente con una Iglesia abstractamente contrapuesta a un Estado, una estructura de dominio "espiritual" frente a la dominación más mecánica y violenta del Estado secularizado. El Nietzsche que lisonjea a la romanidad católica y latina y vitupera la barbarie aldeana de los germanos debería ser recordado también por las plumas manipuladoras que perseveran en presentarle como un padre del nacionalsocialismo. Igualmente, las conexiones entre reflexiones como la de arriba y otras ideas de la época, a saber, la proyectada alianza con el Papa por parte de Augusto Comte, para afianzar su -por qué no decirlo- imperio positivista, heredero - en suma- de la Iglesia Católica, podrían ser tenidas en cuenta.

Pero los dos polos geográficos (Norte-Sur), o etnolingüísticos (barbarie germánica-latinidad), pueden confundirnos. También es derivada, no primaria, la distinción religiosa (protestantes-católicos; politeísmo-monoteísmo). Evidentemente, estas polarizaciones se hayan muy interrelacionadas pero derivan, posiblemente, de un antagonismo más primitivo, presente en sociedades prehistóricas, y seguramente no exclusivo de aquellas más cercanas a nosotros en el momento de acercarse a la luz de la Historia: me refiero a las sociedades indoeuropeas y las semitas. El antagonismo entre nobleza y sacerdocio, por un lado, y el antagonismo entre nobleza y comerciantes, por el otro, es la raíz de la cultura de Occidente. Sus contradicciones, desde hace miles de años, son contradicciones de hoy. Europa no se salvará de su muerte y colonización, siguiendo a Nietzsche y a

ist kein Zweifel; und ebenso wuchs durch sie die Beweglichkeit und Unruhe des Geistes, sein Durst nach Unabhängigkeit, sein Glaube an ein Recht auf Freiheit, seine "Natürlichkeit". Will man ihr in letzterer Hinsicht den Wert zugestehen, Das vorbereitet und begünstigt zu haben, was wir heute als "moderne Wissenschaft" verehren, so muss man freilich hinzufügen, dass sie auch an der Entartung des modernen Gelehrten mitschuldig ist, an seinem Mangel an Ehrfurcht, Scham und Tiefe, an der ganzen naiven Treuherzigkeit und Biedermännerei in Dingen der Erkenntnis, kurz an jenem Plebejismus des Geistes, der den letzten beiden Jahrhunderten eigentümlich ist und von dem uns auch der bisherige Pessimismus noch keineswegs erlöst hat, - auch die, "modernen Ideen" gehören noch zu diesem Bauernaufstand des Nordens gegen den kälteren, zweideutigeren, misstrauischeren Geist des Südens, der sich in der christlichen Kirche sein größtes Denkmal gebaut hat. Vergessen wir es zuletzt nicht, was eine Kirche ist, und zwar im Gegensatz zu jedem "Staate": eine Kirche ist vor Allem ein Herrschafts-Gebilde, das den geistigeren Menschen den obersten Rang sichert und an die Macht der Geistigkeit soweit glaubt, um sich alle gröberen Gewaltmittel zu verbieten, - damit allein ist die Kirche unter allen Umständen eine vornehmere Institution als der Staat. — [íbid.] 
Spengler, si no es capaz de salir de ellas, si no puede polarizarse a favor del polo "noble" de las mismas.

\section{Religión: ¿opio o veneno? El Cristianismo moribundo.}

El sacerdocio, en un principio, fue un trasunto de la nobleza. En efecto su prestigio, su autoridad, su poder, no era ejercido tanto por la fuerza bruta como por las armas mencionadas justo ahora: por el propio prestigio, la autoridad y el poder que dimanaban de personas fuertes, que se hacían respetar, que sabían de lo divino en cuanto que de lo divino ellos mismos, los sacerdotes nobles, se veían investidos. Druidas o brahmanes eran, al tiempo, conductores de pueblos. Mas los pueblos conducidos no eran, todavía, una "masa". Había estratos, y la jerarquía de castas era, ella misma, decreto de la divinidad.

Fueron los judíos, "pueblo sacerdotal" a decir de Nietzsche, los que profesionalizaron, por así decir, al sacerdote, precisamente porque no era un sacerdote de origen noble, sino un plebeyo que arrastraba la enfermedad como todos los plebeyos resentidos. Doblegaron a la aristocracia y a los reyes hebreos y adquirieron todo el cariz de mediadores. Estos nuevos sacerdotes no eran ya parientes próximos a los nobles ("ingenuos") guerreros, y en su inversión de los valores hablaron a su pueblo del fracaso de quienes luchan con la espada y de quienes se coronaban como reyes de Israel. El pueblo de Dios era, en realidad, el pueblo cautivo de otros hombres, una insignificancia. La sed de venganza judía no se dirigió contra enemigos reales, contra pueblos vecinos y opresores de carne y hueso. La sed hubo de saciarse con los propios estratos nobles de los judíos, contra los mejores y más vigorosos. Era preciso nivelar al pueblo para que el sacerdocio se encumbrara. Era preciso formar un rebaño de ovejas y mentir sistemáticamente a ese ganado. El sacerdocio como pastoreo de pueblos consistió, desde entonces, en una gran mentira, en una horrenda interpretación tergiversada de los hechos. La moral noble consistía en la espontaneidad de las fuerzas vitales, que asestan el golpe, lo esquivan, lo evitan, etc. como hechos brutos de la naturaleza, hechos en los que no cabe "interpretación" ni menos aún re-sentimiento. La acción que naturalmente brota de centros de vigor y depósitos de instinto, era la acción que constituía el todo, el ser. La invención de un plano sobrevolado a esta acción y a estos sistemas animales de instintos, es la invención de la moral. De una religión primaria, amoral, donde se busca en el Dios la fuerza, el poder, la salud, se pasa a una religión moralizada, secundaria. Se inventa la moral, es decir, las tablas de interpretación falseada de la realidad, tablas tan mentirosas que sustituyen a la propia realidad y la calumnian. Esta religión secundaria, moral, no es posible sin invenciones y mentiras y la casta sacerdotal necesita formarse como cuerpo profesional de la mentira y la calumnia.

La Europa pagana, ya hablemos de romanos, celtas o germanos, era una Europa ajena a ese cuerpo especializado en la mentira. Las funciones sacerdotales en estos pueblos antes de su cristianización era solidaria del ejercicio de las atribuciones de los nobles. El carácter trifuncional de éstos pueblos exigía un saber y una magia que acompañara y diera respaldo sacro a los bien nacidos. Los propios bien nacidos nutrían las filas de sus magos o 
desempeñaban funciones sacerdotales. Pero el advenimiento del cristianismo , en una Roma que ya había disgregado la fortaleza étnica de muchos de los pueblos indoeuropeos a ella sojuzgados, supuso la intrusión de una casta sacerdotal especializada, al estilo judaico, reconvertida ahora en casta cosmopolita, universal. El sacerdote cristiano podía ser ya hombre de cualquier raza y de cualquier extracción social. El plebeyo podía encumbrarse, el noble podía mutilarse, todos podían nutrir esta casta.

La naturaleza de la Iglesia debe ser comprendida de forma relativa. Depende de con qué se la compare. Solamente así podemos formar una idea de su poder, de sus artes, de su retorcida voluntad de poder. Más arriba, hemos escuchado a Nietzsche en su valoración de la Iglesia como institución más sutil, más sabia que los Estados modernos, toscos y de raíz violenta. Pero por otro lado, la vieja experiencia de la Iglesia (dos mil años de mentira y dominación) ha de compensar su alicorta inteligencia, su intrínseca y vulgar capacidad de adaptación. Leamos el aforismo 70 de Aurora:

70. Para qué sirve una inteligencia tosca. La Iglesia cristiana es una enciclopedia de cultos antiguos, de concepciones de innumerables orígenes, y ésta es la razón de que haya tenido tanto éxito en sus misiones. Tanto antes como ahora podía ir a todas partes con la seguridad de que siempre encontraría algo afín a ella, algo que podría asimilar, insuflándole poco a poco su espíritu. La causa de la expansión de esta religión universal no ha sido lo que contiene de cristianismo, sino lo que hay en sus prácticas de universalmente pagano. Sus ideas, cuyas raíces se encuentran a un tiempo en el espíritu judío y en el espíritu helénico, supieron superar, desde un primer momento, tanto las diferencias y sutilezas raciales y nacionales, como los prejuicios. Con todo, por muy admirable que sea esta capacidad de casar los elementos más dispares, conviene no olvidar sus cualidades despreciables: su asombrosa tosquedad, esa cortedad de inteligencia de la Iglesia en el período

\footnotetext{
${ }^{4}$ Las llamadas "invasiones bárbaras" no fueron la causa del declive de Roma, como ya es reconocido. Fue la búsqueda de solar, la fundación de "patrias", lo que movió a estos pueblos a poblar por encima de los cadáveres institucionales romanos (las pseudomorfosis, en términos de Oswald Spengler). Pero en el asentamiento de godos, de francos, de suevos, en medio de provincias antaño romanas, en el origen mismo del medievo, hubo de darse convivencia y pacto con los sacerdotes. La barbarie no era lo bastante poderosa como para deshacer a la Iglesia. Desde hacía mucho, todo pueblo dirigido por nobles guerreros conoció la tensión entre éstos y los sacerdotes. Dos formas de poder, el físico y el mágico-espiritual, dos expresiones de la voluntad de poder que recelan entre sí, que se odian en lo más hondo, por más que en situaciones de equilibrio (tal fue el caso de los godos hispanos, especialmente en su conversión al catolicismo, pero también antes) se muestren ante el pueblo bajo como un amistoso concilio, como un solo Poder bicéfalo. Los pueblos celtogermanos de Europa, esa materia prima que dio origen a lo que somos hoy, los viejos europeos de la decadencia, no contaron con la fuerza suficiente, con la experiencia política y cultural necesaria como para asimilar por completo los últimos restos de la pseudomorfosis. Pues entre los esqueletos de Roma había parásitos y necrófagos que, sacando partido de la muerte, ellos mismos estaban vivos y se habían dotado de una capacidad de resistencia, de un anhelo por la supervivencia, muy difíciles de superar.
} 
de su formación que le permitió adaptarse a todos los regímenes y digerir contradicciones como si fueran piedras. ${ }^{5}$

La voluntad de poder del espíritu vulgar se disfraza de "cercanía". Cristianizar santuarios paganos, alagar simultáneamente los oídos del bárbaro y del romano, del gentil y del judío, hermanarse con todos bajo una misma bóveda (el cristianismo "mágico" o "cueviforme" de Spengler), todo esto estuvo en manos de la primera Iglesia. La gran venganza y el inmenso resentimiento del "pueblo elegido" pudo llevarse a cabo por medio de una universalización de su proyecto de tomar el poder. Hubo que sacrificar la propia exclusividad judaica para llevar a cabo una judaización universal. La Humanidad entera había de ser pastoreada por un sacerdocio: el Pueblo de Dios. Los albores de Europa, esto es, el nacer de sus pueblos de entre las ruinas de la latinidad, poseen este pecado original: el abandono -nunca total, pues la religiones nunca mueren del todo- del paganismo, el olvido de las más antiguas jerarquías, la polarización de la vida hacia un mundo inventado: el mundo del deber ser.

Pero frente al cristianismo "mágico", enteramente levantino, el producto mestizo de religión semítica y civilización helenística, surge un cristianismo "fáustico". El europeo nace en torno al año 1000 como hombre de una cultura de acción, donde vive como creador de mundos y buscador de infinitos, aun a costa de su propia perdición. El espíritu de Reconquista y de Cruzada, la aguja del gótico, la infinitud vertical ${ }^{6}$.El Norte "aldeano", a decir de Nietzsche, comienza a escucharse a sí mismo, en su propia lengua, a usar su propio Fuero. Lejos del desprecio que Nietzsche siente por lo "aldeano", Spengler, muy al contrario, equipara la nobleza originaria de Europa con el aldeano. El noble no es otra cosa que el miembro de un estrato superior de la clase aldeana: ambos arraigan en el suelo, son plantas de una tierra, poseen vocación de eternidad. El noble y el aldeano perdieron a su antiguo oficiante religioso (un druida, un

\footnotetext{
${ }^{5}$ Aurora, ed. castellana, ibid. Original en lengua alemana: "Wozu ein grober Intellekt nütze ist. - Die christliche Kirche ist eine Enzyklopädie von vorzeitlichen Kulten und Anschauungen der verschiedensten Abkunft und deshalb so missionsfähig: sie mochte ehemals, sie mag jetzt kommen, wohin sie will, sie fand und findet etwas Ähnliches vor, dem sie sich anpassen und dem sie allmählich ihren Sinn unterschieben kann. Nicht das Christliche an ihr, sondern das Universal-Heidnische ihrer Gebräuche ist der Grund für die Ausbreitung dieser Weltreligion; ihre Gedanken, die zugleich im Jüdischen und im Hellenischen wurzeln, haben von Anbeginn an über die nationalen und rassemäßigen Absonderungen und Feinheiten, gleich als über Vorurteile, sich zu erheben gewusst. Mag man diese Kraft, das Verschiedenste in einander wachsen zu lassen, immerhin bewundern: nur vergesse man auch die verächtliche Eigenschaft dieser Kraft nicht, - die erstaunliche Grobheit und Genügsamkeit ihres Intellektes in der Zeit der Kirchenbildung, um dergestalt mit jeder Kost fürlieb zu nehmen und Gegensätze wie Kieselsteine zu verdauen.[íbid.].

${ }^{6}$ El Cristianismo faústico de Spengler es radicalmente distinto del "mágico". El cristianismo mágico, el espíritu levantino de la Cueva, seguía latiendo en el Sur. Los mozárabes oprimidos por el Islam. Los provenzales dualistas, cátaros o albigenses; Bizancio...Las masas urbanas, prestas a cambiar de amo si con ello comen un poco mejor o reciben más espectáculos, pagan menos tributos, ese proletariado pre-industrial, siempre presente en el Sur latino y levantino, no conocía grandes distingos entre el Dios uno y trino defendido por Roma, y la unicidad radical de judíos y árabes. Las disputas teológicas se dejaban en manos de teólogos: la masa urbana, sin raíces, tiene por fuerza que habitar entre pseudomorfosis: restos de derecho romano, nostalgia del Imperio, latín corrupto, piedras y columnas romanas reutilizadas
} 
chamán) en los oscuros tiempos de la cristianización, pero enviaron a hijos suyos a formar parte de la nueva casta. Se completó la "venganza del cristianismo contra Roma" (Aurora, 71). La Iglesia ya no formó parte de una bicefalia, la segunda cabeza del emperador. La Iglesia se alzó sola por sobre la barbarie. Pero Nietzsche (y sí, por el contrario, Spengler) no desarrolla aquí lo que fue la oportunidad de esos bárbaros, aldeanos, esas "bestias rubias" que pudieron volver a levantar la cabeza una vez caída la opresión imperial.

71. La venganza cristiana contra Roma. Quizá no haya nada que hastíe tanto como un perpetuo vencedor. Durante doscientos años se había visto que Roma sometía a un pueblo tras otro; el círculo se había cerrado; daba la impresión de que el futuro estaba totalmente paralizado; todo parecía dispuesto a durar eternamente, a tener el carácter perenne del bronce. Quienes no conocemos otra melancolía que la de las ruinas, apenas podemos concebir esa otra melancolía tan distinta: la de las edificaciones eternas; melancolía de la que habría que defenderse como fuera; por ejemplo, con la ligereza de

Horacio. Otros buscaron distintos consuelos contra un cansancio rayano en la desesperación, contra el mortal convencimiento de que, en adelante, no había esperanza alguna para la acción de la inteligencia y del corazón, de que en todas partes acechaba la araña fatal que succionaría implacablemente toda la sangre que manara. Ese odio mudo del espectador cansado, que ya duraba un siglo, ese odio contra Roma en todos los lugares que ésta dominaba, acabó por descargarse en el cristianismo, que metía en un mismo saco condenable a Roma, al mundo y al pecado. El cristianismo se vengó de Roma anunciando que el fin del mundo estaba cerca, y abriendo un nuevo futuro -Roma había sabido convertirlo todo en historia de su pasado y de su presente-, un futuro contra el que Roma no podía hacer nada; se vengó de Roma concibiendo el juicio final. Y el judío crucificado, símbolo de salvación, aparecía, ante los orgullosos pretores de las provincias romanas, como el más hondo de los escarnios, ya que aquéllos se convertían en representantes de la perdición y del mundo, maduro ya para su caída. ${ }^{7}$

\footnotetext{
${ }^{7}$ Aurora, 71. Die christliche Rache an Rom. - Nichts ermüdet vielleicht so sehr als der Anblick eines beständigen Siegers, - man hatte Rom zweihundert Jahre lang ein Volk nach dem andern sich unterwerfen sehen, der Kreis war umspannt, alle Zukunft schien am Ende, alle Dinge wurden auf einen ewigen Zustand eingerichtet, - ja wenn das Reich baute, so baute man mit dem Hintergedanken des "aere perennius"; - wir, die wir nur die "Melancholie der Ruinen" kennen, können kaum jene ganz andersartige Melancholie der ewigen Bauten verstehen, gegen welche man sich zu retten suchen musste, wie es gehen wollte, - zum Beispiel mit dem Leichtsinne Horazens. Andere suchten andere Trostmittel gegen die an Verzweiflung grenzende Müdigkeit, gegen das tötende Bewusstsein, dass alle Gedanken- und Herzensgänge nunmehr ohne Hoffnung seien, dass überall die große Spinne sitze, dass sie unerbittlich alles Blut trinken werde, wo es auch noch quelle. - Dieser jahrhundertalte wortlose Hass der ermüdeten Zuschauer gegen Rom, so weit nur Rom herrschte, entlud sich endlich im Christentume, indem es Rom, die "Welt" und die "Sünde" in Eine Empfindung zusammenfasste: man rächte sich an ihm, indem man den plötzlichen Untergang der Welt sich in der Nähe dachte: man rächte sich an ihm, indem man wieder eine Zukunft vor sich stellte - Rom hatte Alles zu seiner Vorgeschichte und Gegenwart zu machen gewusst - und eine Zukunft, in Vergleich zu welcher Rom nicht mehr als das Wichtigste erschien; man rächte sich an ihm, indem man vom letzten Gericht träumte, - und der gekreuzigte Jude als Symbol des Heils war der tiefste Spott auf die prachtvollen römischen Prätoren in der Provinz, denn nun erschienen sie als die Symbole des Unheils und der zum Untergange reifen "Welt". -
} 
La llamada Edad Media no fue -al menos no del todo- un triunfo de la barbarie sobre la civilización. Fue un triunfo de los cristianos sobre Roma, y también una oportunidad para que los paganos (léase, habitantes del pagus, aldeanos) entraran en la Historia, formaran patrias, crearan nuevas jerarquías, compartieran poder con la Iglesia, o la rehicieran en sus propios dominios periféricos a su manera. Nació Europa.

Pero en la actualidad, la Europa vieja ha recibido por completo el veneno sacerdotal. La Religión organizada se llama hoy moral. O si se quiere: "Educación para la Ciudadanía", "Derechos Humanos", "Solidaridad", "Diálogo de Civilizaciones". Es Religión, y una religión a menudo fanática, dispuesta a descargar su ira represiva sobre toda disidencia. Es Religión que decreta, vigila, programa, escruta. Es Religión que hace uso de los aparatos de Estado y de las Instituciones europeas, educativas, jurídicas, etc. para asentar y extender su dominio. La Religión moralizada, ya sin Dios, con un Dios cada vez más cosmopolita, pretende imponer una única vía para administrar el veneno en las venas de la civilización. Una muerte lenta y soporífera que incluye la abyecta entrega a las demás potencias. La civilización de la vieja Europa lo ha perdido todo, o está en trance de ello: la tradición, la religión, la familia, la cortesía, el sentido del deber y del esfuerzo, la conformidad de cada uno con su propio sino, la moderación y la decencia, el pudor y el respeto, el valor del trabajo, la noción de la patria...Por el contrario, el Europeo de la fase decadente, víctima de la más atroz de las alienaciones, tiende a verse a sí mismo como objeto de libre disposición, animal sin esencia. Se puede vender y prostituir. Los cuerpos y los vientres se alquilan, y en los sudores de sus jornadas laborales se va aniquilando su alma. $Y$ quien no es esclavo del Trabajo es, peor aún, parásito de una sociedad opulenta. Los plebeyos de esta nueva Roma quieren pan y circo, quieren grasas fláccidas para soportar el invierno de su propio sudor.

Mientras tanto, ya carente de religión, y especialmente de esa religión que Nietzsche calificó de venenosa y que vino a sustituir al paganismo ancestral, el europeo subsiste con dosis diversas de veneno sutil, suave al tacto y al gusto, pero más letal y corrosivo en su eficacia final: la moral. El hombre helenístico ya fue un pre-cristiano. La decadencia de la religión griega, el socratismo y el platonismo, el triunfo casi entrópico del componente asiático habido desde antiguo en la Grecia clásica, y exacerbado a partir de Alejandro -sino antes, a partir de Sócrates- supuso para Europa su desvirtuación. El apéndice de Asia que llamamos Europa, por obra del imperativo de la Segunda Ley de la Termodinámica (o de un análogo suyo válido en la Historia), tiende a rebajarse, a sumirse en la barbarización. Los griegos recayeron en lo asiático incluso antes del advenimiento del cristianismo. Al verterse sobre Asia, lo que ocurrió realmente fue que Asia volvió sobre ellos y reclamó una parte que era suya y que en las catacumbas de su alma ya existía. Otros ejemplos históricos análogos podríamos ofrecer de este proceso entrópico que es, a la par, una exacerbación de tendencias internas. En Occidente, el modelo de lo que ha de 
ser Imperium, Roma, consiste siempre en una voluntad señorial que organiza la pluralidad en una unidad: el derecho, el ejército, la lengua, todos los instrumentos de la civilización romana fueron puestos al servicio de esa voluntad de poder, la de un pueblo que se quiso a sí mismo y que en todo otro pueblo exige sumisión y asimilación. "Romanizar" el mundo fue verter ese mundo a sus moldes, "traducir" a la lengua del Imperio todo lo otro. El continuum que se puede establecer entre lo Romano y lo Hispánico es un hecho evidente. Ningún otro programa recto de asimilación de lo ajeno tuvieron los españoles en su conquista del sur peninsular, el sur moro, en su guerra al turco y al protestante, en su conquista y organización imperial de las Indias.

Los dos grandes Imperios, romano e hispánico, fueron voluntades de poder, imperativos de traducción cultural: interpretar el mundo de una forma universal. Pero Roma sucumbió al helenismo y a la orientalización: su Imperium se transformó, a decir de Spengler, en una cueva. Las provincias celtogermánicas quedaron pronto devueltas a pueblos afines en el fondo, vigorosos en la guerra: las Galias, el Norte de Hispania, Centroeuropa... Sobre los cadavéricos restos de su romanismo (pseudomorfosis) nacería Europa, una Europa faústica. Por el contrario, en el entorno mediterráneo, y pese a la parcial disrupción que provocaron la decadencia del poder centralizado, la acción de los piratas y bárbaros, en suma, la pérdida de seguridad en el tráfico por el Mare Nostrum, la continuidad espiritual es impresionante. La Bética de los visigodos siguió siendo muy romana y bizantina, y después musulmana, es decir, oriental y cueviforme. Un soplo de Asia siempre llegó hasta las Columnas de Hércules. Cuando los conversos bereberes llegaron a la actual Andalucía, en plena decadencia goda, como nuevos bárbaros al servicio de élites árabes, no venían sino a recuperar lo que ya entendían los conquistadores como suyo: un trozo de Asia. No se es conquistador en el sentido imperial de la palabra, si no hay previa voluntad de fagocitar lo que ya se ve como propio. $^{8}$

Ahora, la segmentación social se está dando en la propia Metrópoli, en la vieja Europa. Una Europa dividida en pequeños estados, nacionales 0 plurinacionales, y que se ha dejado colonizar o segmentar por los

\footnotetext{
${ }^{8}$ Hoy en día, Europa no es Imperio ni federación. Tampoco hay, entre la multitud de estados nacionales que la conforman, una "potencia" que lidere ese impulso unificador, que haga las veces de una Voluntad de Poder. Hasta el propio término "potencia" se nos antoja trasnochado, un vestigio del lenguaje decimonónico. Tras la caída del poder de la URSS - o más bien en su reconversión en una Federación Rusa de dimensiones igualmente imperiales, el término Potencia quedó reservado en exclusiva a los EEUU. El llamado "gendarme de Occidente", su misma existencia, recuerda siempre al filósofo de la historia que no es lo mismo hablar de Europa que de Occidente. Occidente es la generalización de lo europeo, la conclusión del proceso imperialista y colonizador de las viejas potencias del Viejo Mundo. Consiste básicamente en la civilización exportada a América y en el modo de vida transportado por los emigrantes de raza blanca. Ese Occidente que llevó consigo el hombre blanco a otros continentes no es homogéneo en sus rasgos básicos. Los ibéricos fueron a América con los moldes imperiales y desde ellos aportaron caudales de sangre migratoria. Los anglosajones, y tras ellos, nórdicos y centroeuropeos, emigraron bajo cauces coloniales. La lógica imperial y la lógica colonial no son coincidentes. Roma, como España, quiso asimilar el elemento "bárbaro" a su molde formal. Buscó una homogeneidad cultural católica, esto es, universalista. Gran Bretaña, en cambio, hizo transplantes de células anglosajonas en un medio ajeno: el elemento nativo no fue asimilado al molde formal, sino suplantado por células de hombres blancos que proliferaban y se imponían.
} 
desheredados de sus antiguos imperios. Como si obedeciera a un complejo de culpa, la envejecida civilización faústica renuncia a seguir creando y se entrega a su propio suicidio, haciendo de su territorio y de sus pueblos una región planetaria sin defensas. La civilización más vigorosa (no en armas, pero sí quizá en demografía y en valores fanáticos) puede hacerse la dueña. Los europeos que dan la espalda a Bach o a Homero pero bailan frenéticamente la danza del vientre o algún ritmo tribal de la selva ya son una avanzadilla del proceso de que hablamos. La llustración, la Aufklärung que con dialéctica perversa incluye mecanismos entrópicos de disgregación en nombre del multiculturalismo, ha dado todo lo que podía dar de sí. Su sueño utópico de una reforma del pueblo europeo ha devenido en creación de sociedad de masas. No hemos logrado un pueblo filósofo, hemos conseguido únicamente "opinión pública”. El devoto público de los púlpitos reza cada mañana con periódicos y con internet. La Ilustración significó el hombre masa, la combinación perversa de individualismo con instinto gregario, esto es, la mera agregación de cuerpos como sustitutivo de una verdadera sociedad. ${ }^{9}$

Y aquí nos corresponde volver los ojos hacia el Cristianismo, también religión moribunda en tanto que religión europea. Nada diremos del Cristianismo en cuanto religiosidad transportada a América, donde puede hacer mixtura con cultos indígenas o convertirse una y mil veces en soteriología, en discurso "emancipador". Esta religiosidad encuentra el humus perfecto allí donde hay oprimidos, explotados, cautivos: se reencuentra en su esencia. Pero en Europa hace ya tiempo que el Cristianismo es moral, simplemente un jarabe para enfermos, un ungüento para aliviar las heridas de una civilización que se resquebraja. El socialismo de la izquierda tradicional (socialdemocracia, comunismo), una vez perdida su propia voluntad de poder, esto es, el afán de conquistar el mundo de forma revolucionaria, queda reducido a los estrictos límites de un clericalismo laico. Son curas de estirpe luterana y neokantiana los que hablan del "deber" y de los Derechos Humanos. Curas y poco más que curas los que azuzan su Imperativo Categórico en las frentes de los niños, impartiéndoles asignaturas de Educación Ciudadana, enseñando al pueblo lo bueno que es "comprometerse" en forma de afiliación a sindicatos, ONGs y partidos democráticos. Educación para el Consumo, Educación para la Igualdad, Educación afectivo-sexual y Lenguaje Políticamente Correcto...el neokantismo de izquierdas es, hoy en día, el medicamento somnífero preferido por los Estados moribundos. Es la Religión de este sistema vitalmente exhausto que se empeña en ocultar la horrenda cosificación del hombre, incluyendo aquí al hombre masa europeo, el empeño por hacerle animal y esclavo.

\footnotetext{
${ }^{9}$ La Escuela de Frankfurt describió claramente el proceso de degradación de la Cultura en espectáculo, industria, consumismo, y todo ello como parte del recorrido mismo del proyecto llustrado. De la misma manera que los philosophes nos han traído no a una República de Sabios sino a lectores de periódicos e "ideas modernas", en palabras Nietzsche, es decir, la masa, hoy sus epígonos -los intelectuales- no pueden sino culminar el proceso dialéctico: más "progreso" al servicio de una tecnología y de una excitación infinita de las ganas de consumir. Este progreso significa hacer reventar desde dentro la cultura que lo generó como idea rectora (idea faústica, que no conoce fin). El progreso es la Religión del europeo, el cristianismo moralizado, la moral como cataplasma para una civilización moribunda.
} 